\title{
Aspek Hukum Internasional Dalam Pemanfaatan Deepfake Technology Terhadap Perlindungan Data Pribadi
}

\author{
Muhammad Ariq Abir Jufri*; Akbar Kurnia \\ Fakultas Hukum, Universitas Jambi \\ *Corresponding author: ariqaljufri@gmail.com
}

$\begin{array}{ll}\text { Submission } & : 22 \text { November } 2020 \\ \text { Revision } & : 27 \text { Februari } 2021 \\ \text { Publication } & : 18 \text { Maret } 2021\end{array}$

\begin{abstract}
The purpose of this research is to knowwhat the aspects of international law in regards to the use of deepfake technology relating to personal data protection are, and how it impacts the Indonesia's national law based on the law principle of social engineering which dictates that the law is created to guide people towards a better way, and the principle of social controlling as a planned process to force people to abide by the customs, norms and other values held by society so there won't be any deviated behaviours specifically in the use of deepfake technology, and how to align international and national law using the principle of planning, organizing, actuating, and controlling. This research uses a normative law type of approach. The source of data used consists of: a) Primary legal material, such as Convention 108+, Convention for the Protection of Individuals with Regards to the Processing of Personal Data; Constitution and Convention of the international telecomunication union (with annexes and optional protocol). Concluded at Geneva on 22 December 1992; Republic of Indonesia's Act No. 19 (of) 2016 about Electronic and Information Transaction; b) As for the secondary legal material used are books, articles, journals, reports, and various scientific papers and etc. Which supports the primary legal material; c) As for the tertiary legal materials used are dictionaries, interviews, newspaper, the internet, and etc. Which can support both the primary and secondary legal materials. Data analysis
\end{abstract}


are conducted in a descriptive-qualitative manner. This research specified the use of descriptive analysis.

Keywords: Deepfake, Legal Protection, Personal Information.

\begin{abstract}
Abstrak
Tujuan penelitian ini adalah untuk mengetahui bagaimanakah aspekaspek hukum internasional dalam pemanfaatan Deepfake Technology terhadap perlindungan data pribadi dan dampaknya terhadap hukum nasional Indonesia berdasarkan dengan Prinsip Hukum Social Engineering yaitu hukum diciptakan sebagai sedemikian rupa untuk mengarahkan perubahan ke arah yang lebih baik dan Social Controlling merupakan proses yang direncanakan untuk memaksa seseorang untuk mentaati kebiasaan, norma dan nilai hidup di masyarakat agar tidak terjadinya perilaku menyimpang dalam pemanfaatan teknologi Deepfake serta cara menyelaraskan aturan hukum internasional dengan prinsip Planning, Organizing, Actuating dan Controlling. Tipe penelitian ini adalah penelitian hukum normatif. Sumber data yang digunakan terdiri dari: a) bahan hukum primer, yaitu Convention 108+, Convention for the Protection of Individuals with Regard to the Proccessing of Personal Data; Constitution and Convention of the International Telecommunication Union (with annexes and optional protocol). Concluded at Geneva on 22 December 1992; Undang-Undang Negara Republik Indonesia Nomor 19 Tahun 2016 Tentang Informasi dan Transaksi Elektronik; b) Adapun bahan hukum sekunder yang digunakan berupa buku, artikel, jurnal penelitian, laporan penelitian, berbagai karya tulis ilmiah dan sebagainya yang dapat menunjang bahan hukum primer; c) Adapun bahan hukum tersier yang digunakan berupa kamus, wawancara, surat kabar, internet, dan sebagainya yang dapat menunjang bahan hukum primer dan sekunder.
\end{abstract}

Kata Kunci: Data Pribadi, Deepfake Technology, Perlindungan Hukum.

\title{
A. Pendahuluan
}

Hukum Internasional dapat didefinisikan sebagai keseluruhan hukum yang untuk sebagian besar terdiri dari prinsip-prinsip dan kaidah-kaidah perilaku yang terhadapnya negara-negara merasa dirinya terikat untuk mentaati, dan karenanya, benar- 
Aspek Hukum Internasional dalam Pemanfaatan Deepfake...

benar ditaati secara umum dalam hubungan-hubungan mereka satu sama lain. ${ }^{1}$ Berdasarkan definisi tersebut dapat dilihat bahwa hukum menjadi salah satu sistem yang terpenting dalam pelaksanaan atas rangkaian kekuasaan kelembagaan, terutama di ranah internasional.

Pada esensinya hukum memiliki kapasitas untuk bertindak sebagai instrumen Social Engineering dan Social Controlling. Di mana hukum sebagai sarana Social Engineering adalah penggunaan hukum secara sadar untuk mencapai suatu tertib atau keadaaan masyarakat sebagaimana di cita-citakan atau untuk melakukan perubahan-perubahan yang diinginkan² dan Social Controlling merupakan keterlibatan hukum dalam upaya teknik dan strategi yang mencegah perilaku manusia untuk menyimpang dalam masyarakat, ${ }^{3}$ kedua hal ini menggambarkan sifat hukum dimana hukum menjadi faktor penentu kehidupan masyarakat dan dimana hukum menyesuaikan dengan perkembangan dari masyarakat itu sendiri. Mengingat di masa mutakhir ini kehidupan manusia tidak terlepas dari teknologi, maka pengaturan yang mengiringi arah berkembangnya teknologi menjadi sesuatu yang krusial atau diperlukan.

1 J.G. Starke, Pengantar Hukum Internasional, Cet. 10, Sinar Grafika, Jakarta, 2010, Hal. 3.

2 Satijpto Rahardjo, Hukum Progresif: Sebuah Sintesa Hukum Indonesia. Yogyakarta: Genta Publishing. 2009, Hal. 128.

3 Ibid., Hal. 129. 
Berkaitan dengan konsepsi negara hukum maka Pasal 1 ayat (3) UUD 1945 menegaskan bahwa: "Indonesia adalah negara hukum." Bermakna adanya pengakuan normatif dan empirik terhadp prinsip supremasi hukum; semua masalah diselesaikan dengan hukum sebagai pedoman tertinggi. Dalam perspektif supremasi hukum pada hakekatnya pemimpin tertinggi negara sesungguhnya bukanlah manusia tetapi konstitusi yang mencerminkan hukum yang tertinggi. Sejalan dengan kemunculan ide demokrasi konstitusional yang tak terpisahkan dengan konsep negara hukum, baik Rechtstaat maupun Rule of Law, pada prinsipnya memiliki kesamaan yang fundamental, yakni pengakuan pentingnya adanya pembatasan kekuasaan yang dilakukan secara konstitusional. Oleh karena itu, terlepas dari adanya pemikiran dan praktik konsep negara hukum yang berbeda, konsep negara hukum adalah realitas dari cita-cita sebuah negara bangsa, tidak terkecuali bagi Indonesia. ${ }^{4}$

Menurut Black's: Law Dictionary, teknologi merupakan "Pengaplikasian informasi untuk desain, produksi, dan pemanfaatan atau utilisasi suatu pelayanan dan benda-benda serta pengorganisiran aktivitas manusia". ${ }^{5}$ Meski teknologi dan

4 Retno Kusniati, Jurnal Sejarah Perlindungan Hak Hak Asasi Manusia Dalam Kaitannya Dengan Konsepsi Negara Hukum. Jurnal Ilmu Hukum, Vol. 4. No. 5. 2011, https://online journal.unja.ac.id/jimih/article/view/536

5 Black's: Law Dictionary Online, https://thelawdictionary.org/ technology/. 
hukum merupakan dua bidang yang berbeda, namun keduanya memiliki tujuan yang saling berkaitan antara satu sama lain, yaitu untuk meningkatkan kesejahteraan manusia. Teknologi dapat mengubah perilaku dan pola hidup masyarak secara global. Perkembangan teknologi informasi telah menyebabkan dunia menjadi tanpa batas dan menyebabkan perubahan sosial, budaya, ekonomi serta pola penegakan hukum yang secara signifikan berlangsung demikian cepat. Pada perkembangan teknologi mutakhir telah mencetuskan suatu teknologi kecerdasan buatan atau Artificial Intelligence (AI) yang mana eksistensinya belum di atur konkrit dalam Hukum Internasional. Menurut Russel Stuart dalam bukunya: "Artificial Intelligence is often used to describe machines (or computers) that mimic "Cognitive" functions that humans associate with the human mind, such as "Learning" and "Problem Solving".6 Terjemahan bebas dapat diartikan bahwa AI atau kecerdasan buatan adalah istilah yang kerap dipergunakan untuk mendeskripsikan mesin-mesin berhitung (komputer) yang meniru fungsi-fungsi "Cognitive" (kecerdasan) yang dimiliki oleh manusia, seperti untuk belajar dan menyelesaikan suatu masalah.

Teknologi AI merupakan permulaan proses produksi dan administrasi memasuki tahapan yang lebih maju dengan

6 Russell, Stuart J.; Norvig, Peter (2009). Artificial Intelligence: A Modern Approach (3rd ed.). Upper Saddle River, New Jersey: Prentice Hall. Hal. 2. 
sistem yang otomatis dan digitalisasi. Meskipun AI muncul pada tahun 1956, tetapi teori-teori yang mengarah ke AI sudah muncul sejak tahun 1941, istilah AI itu sendiri dikemukakan pada tahun 1956 di konferensi Darthmouth.7 Sejak saat itu AI terus dikembangkan mengikuti berbagai penelitian mengenai teori-teori dan prinsip-prinsipnya yang juga terus berkembang.

Berkembanganya AI mencetuskan sebuah algoritma tertentu yang disebut Deepfake Technology. Menurut Marissa Koopman, Andrea Macarulla Rodriguez, dan Zeno Geradts pada jurnalnya memberikan penerangan pada Deepfake Technology sebagai algoritma, berupa: "The Deepfake algorithm allows a user to switch the face of one actor in a video with the face of a different actor in a photorealistic manner".8 Dalam kata lain Deepfake merupakan istilah yang diberikan pada algoritma yang mana algoritma tersebut memungkinkan penggunanya untuk mengubah wajah dari satu aktor menjadi wajah dari aktor lain dalam video yang berbentuk photorealistic. ${ }^{9}$ Dapat diketahui bahwa Deepfake Technology merupakan cara baru untuk memanipulasi videografi dalam

7 Sutojo, T. (2011). Kecerdasan Buatan. Edisi Pertama. ANDI OFFSET. Bandung, Hal. 3.

${ }^{8}$ Detection of Deepfake Video Manipulation, Marissa Koopman, Andrea Macarulla Rodriguez, Zeno Geradts. University of Amsterdam \& Netherlands Forensic Institute 2018.

9 Photorealistic merujuk pada sifat yang berkenaan dengan photorealism dalam artian gaya artistic yang merepresentasikan suatu subjek dalam arah yang akurat dan detil, seperti sebuah fotografi. 
beberapa tahun terakhir, yang dapat digunakan untuk memanipulasi wajah seseorang menjadi wajah orang lainnya dalam bentuk sebuah video.

Lalu apa yang membedakan Deepfake dengan video manipulasi lainnya? Pertama, potensi untuk menjadi hasil Photorealistic; dengan terpenuhnya wajah untuk masingmasing aktor dan dengan waktu yang cukup dalam algoritmanya, maka hasil video tersebut akan terlihat sangat meyakinkan. Kedua, ketersediaan dan mudahnya bagi orang awam untuk mengakses dan mempergunakan aplikasi-aplikasi Deepfake yang tersedia untuk umum, seperti FaceApp, Reface dan sebagainya. Hingga pada tahap saat ini manusia mampu membuat sebuah alat maupun sistem yang dapat mempermudah setiap pekerjaannya, termaksud penggunaan Deepfake.

Meningkatnya pemanfaatan teknologi berupa internet memiliki sisi positif dan negatif didalamnya. Salah satu hal positif yang terkandung adalah mudahnya untuk melakukan pertukaran informasi serta membuka banyak peluang terhadap pengembangan-pengembangan informasi tersebut. Disisi lain terdapat pula aspek negatif yang menjadi kerawanan baru seperti terjadinya intervensi oleh pihak ketiga terhadap privasi, dikarenakan peredaran data dalam bentuk format digital yang tidak mengenal batas ruang dan teritorial, sehingga terjadilah dengan mudah pemindahan data-data 
pribadi ataupun dipindahtangankan secara semena-mena tanpa kendali dari pemilik data tersebut.

Dalam pengaplikasiannya Deepfake telah menarik perhatian luas dikarenakan penggunaan teknologi tersebut di dalam video porno selebriti, berita palsu, hoax, dan penipuan finansial. Hal ini turut mengundang tanggapan dari pihak industri ataupun pemerintahan untuk mendeteksi dan membatasi penggunaannya. ${ }^{10}$ Teknologi Deepfake memanfaatkan data berupa wajah dari individu yang merupakan bagian dari data pribadi dan berpotensi untuk disalah gunakan, baik itu untuk tindakan kejahatan seperti, propaganda, pornografi, pencurian identitas ataupun isu privasi terkait lainnya.

Profesor asosiasi ilmu komputer Hao Li dari University of Southern California menyatakan bahwa Deepfake yang dibuat untuk penggunaan jahat, seperti berita palsu, akan lebih berbahaya jika tidak ada langkah yang dilakukan dalam menyebarkan kesadaran akan teknologi Deepfake tersebut. ${ }^{11}$ Li memperkirakan bahwa video asli dan Deepfake akan sampai pada titik hingga tidak dapat dibedakan dalam waktu setengah

10 Clarke, Yvette D, (28 June 2019), "H.R.3230 - 116th Congress (20192020): Defending Each and Every Person from False Appearances by Keeping Exploitation Subject to Accountability Act of 2019". www.congress.gov

11 "Perfect Deepfake Tech Could Arrive Sooner Than Expected", www.wbur.org

Uti Possidetis: Journal of International Law, Vol. 2, No. 1 (2021) 
tahun, terhitung semenjak Oktober 2019, karena kemajuan pesat dalam kecerdasan buatan dan grafik komputer. ${ }^{12}$

Pemanfaatan internet di masa dewasa ini juga ikut berpengaruh besar dengan kaitannya dalam berbagai bidang kehidupan yang tidak hanya membuat segala sesuatunya menjadi lebih mudah, akan tetapi juga menimbulkan sejumlah permasalahan termasuk masalah hukum. Salah satu masalah hukum yang timbul adalah masalah yang berkaitan dengan perlindungan data pribadi (the protection of privacy rights). Dengan demikian, kehadiran regulasi yang mengatur isu pemanfaatan teknologi Artificial Intelligence khususnya yang memanfaatkan penggunaan algoritma Deepfake dalam sektor perlindungan data pribadi adalah suatu kebutuhan.

Butir (a) dari Pasal 2, Europe's Convention 108+, merumuskan bahwa "personal data' means any information relating to an identified or identifiable individual (data subject)".13 Atau dalam bahasa Indonesia: "data pribadi" diartikan sebagai setiap informasi terkait individu yang teridentifikasi atau dapat diidentifikasi (data subject). Tiaptiap negara menggunakan peristilahan yang berbeda antara informasi pribadi dan data pribadi. Meski demikian secara substantif keduanya memiliki pengertian yang hampir serupa sehingga kedua istilah tersebut sering bergantian dalam

12 Ibid.

13 Convention for the protection of individuals with regard to the processing of personal data, Article 2, Verse a.

Uti Possidetis: Journal of International Law, Vol. 2, No. 1 (2021) 
penggunaannya. Australia, Amerika Serikat, dan Kanada menggunakan istilah informasi pribadi sedangkan NegaraNegara di Uni Eropa dan Indonesia sendiri dalam UndangUndang Informasi dan Transaksi Elektronik menggunakan istilah data pribadi.

Dengan berdasarkan pemanfaatan fungsi hukum sebagai instrumen Social Engineering, hukum yang diciptakan sebagai sedemikian rupa untuk mengarahkan perubahan ke arah yang lebih baik dan Social Controlling, proses yang direncanakan untuk mendidik, mengajak atau memaksa seseorang mengikuti nilai-nilai yang berlaku (kebiasaan, norma, dan nilai-nilai yang hidup dimasyarakat). ${ }^{14}$ Maka diperlukan aturan Hukum Internasional guna untuk mencegah perilaku menyimpang dari manusia dalam pemanfaatan Deepfake Technology.

\section{B. Pembahasan}

1. Aspek Hukum Internasional Mengenai Deepfake Technology Terkait Perlindungan Data Pribadi.

Pada bab sebelumnya telah dijelaskan bahwa, aspekaspek hukum merupakan suatu penginterpretasian atau bahkan komponen secara langsung yang bertindak sebagai sumber dalam berbagai sudut pandang di ranah hukum. Dalam Hukum Internasional yang dikaitan dengan Deepfake Technology, dapat ditemukan salah satu instrumendalam

14 Tim Pengajar Mata Kuliah Pengantar Ilmu Hukum Universitas Jambi, Buku Ajar Penghantar Ilmu Hukum, Buku I, Hal. 62-64. 
bentuk persatuan, berupa International Telecommunication Union. Lalu mengapa International Telecommunication Union relevan dalam isu ini? Pada website Library of Congress menjelaskan tentang fungi ITU yaitu, The ITU is a specialized agency of the UN for information and communication technologies, and "has become one of the key UN platforms for exploring the impact of $A I^{\prime \prime} .15$ Dapat terjemahkan bahwa, ITU merupakan suatu badan PBB yang dikhususkan untuk teknologi informasi dan komunikasi, dan "telah menjadi salah satu platform utama PBB dalam pengeksplorasian dampak dari $\mathrm{AI}^{\prime \prime}$.

Dengan menggunakan teori perlindungan kita dapat melihat terdapatnya suatu kepentingan yang mana kepentingan tersebut dilindungi oleh hukum. Kelahiran suatu persatuan yang memiliki upaya untuk menyatukan hukumhukum positif dalam satu kelarasan, terutama mengenai teknologi dan perkembangannya, dapat menjadi penanda bahwa teknologi merupakan bagian dari kepentingan tersebut. Deepfake Technology sendiri adalah salah satu perkembangan teknologi yang dikaitkan dengan data pribadi. Sehingga dalam hal ini, kepentingan yang dilindungi adalah berupa kepentingan pribadi yang merujuk pada hak-hak, pengunaan serta penyimpanan dari data pribadi tersebut.

15 Library of Congress: Regulation of Artificial Intelligence: International and Regional Approaches, https://www.loc.gov/la w/help/artificial-intelligence/international.php\# ftn7

Uti Possidetis: Journal of International Law, Vol. 2, No. 1 (2021) 
Dikarenakan Deepfake technology merupakan algoritma yang memungkinkan penggunanya untuk mengubah wajah dari satu orang menjadi wajah dari orang lain dalam video yang berbentuk photorealistic dan bahwa pengunaannya tidak menutup kemungkinan untuk melibatkan peran lintas batas negara, dalam artian penyalahgunaannya pun dapat pula merugikan pihak-pihak yang berkedudukan atau berkewarganegaraan asing, termaksud Indonesia, di saat perbuatan tersebut dilangsungkan di negara lain. Berdasarkan hal ini, maka dapat dilihat bahwa aspek hukum internasional yang setidaknya memayungi segala aturan hukum domestik agar tidak saling tumpang tindih dan tidak memiliki cangkupan hukum yang sangat berbeda.

Deepfake Technology merupakan algoritma yang memungkinkan penggunanya untuk mengubah wajah dari satu aktor menjadi wajah dari aktor lain dalam video yang berbentuk photorealistic. Seiring dengan perkembangan teknologi seharusnya perkembangan hukum harus selalu menyesuaikan. Aturan hukum mengenai Deepfake Technology belum diatur secara Hukum Internasional. Untuk saat ini Hukum Internasional memberikan keleluasaan bagi masingmasing negara untuk memiliki aturannya sendiri terkait penggunaan teknologi dalam bidang informasi, meski demikian Hukum Internasional juga telah memiliki beberapa upaya dalam menyelaraskan aturan terkait hal tersebut, salah satunya yang ditemukan penulis dalam Convention of the International 
Telecommunication Union yang di mana Pasal 1 dalam konvensi tersebut mengemukakan tujuan dari International Telecommunication Union berupa: ${ }^{16}$

A. to maintain and extend international cooperation between all Members of the Union for the improvement and rational use of telecommunications of all kinds;

B. to promote and to offer technical assistance to developing countries in the field of telecommunications, and also to promote the mobilization of the material and financial resources needed for implementation;

C. to promote the development of technical facilities and their most efficient operation with a view to improving the efficiency of telecommunication services, increasing their usefulness and making them, so far as possible, generally available to the public;

D. to promote the extension of the benefits of the new telecommunication technologies to all the world's inhabitants;

E. to promote the use of telecommunication services with the objective of facilitating peaceful relations;

F. to harmonize the actions of Members in the attainment of those ends;

G. to promote, at the international level, the adoption of a broader approach to the issues of telecommunications in the global information economy and society, by cooperating with other world and regional intergovernmental organizations and those non-governmental organizations concerned with telecommunications.

Merujuk pada salah satu tujuan dari International Telecommunication Union khususnya butir " $\mathrm{g}$ " yang

16 Constitution and Convention of the International Telecommunication Union (with annexes and optional protocol). Concluded at Geneva on 22 December 1992, Article1. 
menyatakan bahwa mereka memiliki tujuan untuk mempromosikan pada skala internasional, adopsi atas pendekatan yang lebih luas terhadap isu-isu telekomunikasi didalam peradaban informasi dan ekonomi global; dengan cara bekerjasama dengan organisasi-organisasi antar pemerintahan serta organisasi non-pemerintahan yang khawatir dengen telekomunikasi. Hal ini membuktikan General Concern terkait perkembangan teknologi dan dibutuhkannya perbaharuan/penambahan/pengadaan aturan hukum terhadap Hukum Internasional mengenai teknologi yang bersifat saling berkesinambungan dan tidak kontra, bagi masyarakat internasional.

Mengapa Deepfake technology perlu diatur pada skala internasional? Karena video Deepfake dapat mengundang kericuhan sosial yang dapat melahirkan teori konspirasi palsu. Deepfake dapat menyebarkan berita ujaran kebencian yang meliputi SARA, menyebarkan paham radikalisme dan menjadi alat propaganda jika terjadi konflik antar suatu golongan serta dapat menjadi alat politik seperti contoh kasus Donald Trump menyebarkan video Deepfake dari Nancy Pelosi serta video Barack Obama dan Alexandria Ocasio-Cortez yang dapat dilihat tayangannya di Youtube. ${ }^{17}$ Kemunculan Deepfake dari sejumlah

17 CBS This Morning, Doctored Pelosi video highlights the threat of deepfake tech, https://www.youtube.com/watch?v=EfREntgxmDs , diakses pada 13 November 2020. 
politisi ternama akan mempengaruhi Netizen, ${ }^{18}$ karena setiap pengguna internet tidak semuanya memiliki edukasi yang sama terkait deepfake technology. Seiring berjalannya waktu kualitas video Deepfake akan semakin berkembang jika semakin sempurna teknik memanipulasi video ini maka akan semakin sulit untuk mengidentifikasi apakah suatu video tersebut asli atau merupakan teknik Deepfake. Dimasa yang mendatang maka kita sangat sulit untuk mempercayai apa yang kita lihat dan yang kita dengar. Jika tidak ada aturan Hukum Internasional yang mengatur tentang Deepfake dan disertai semakin berkembangnya teknologi terkait maka teknik ini berpotensi untuk disalahgunakan.

Pasal 8 Konvensi Hak Asasi Manusia merumuskan, bahwa badan-badan publik diharuskan untuk menghormati kehidupan pribadi dari individu dan setiap informasi yang disimpan terkaitnya. ${ }^{19}$ Mereka diwajibkan untuk mampu melakukan penyimpanan atau pemerosesan personal data manapun yang memadani. Konvensi yang sama juga menyatakan bahwa pemerintah-pemerintah memiliki kewajiban untuk memastikan hukum nasionalnya menyediakan proteksi personal data secara umum yang memadai.

18 Netizen memiliki arti Warganet (Warga Internet) merujuk pada orang yang aktif mengakses internet

19 EU Charter of Fundamental Rights, Article 8 - Protection of personal data. 


\section{Dampak Deepfake Technology Terkait Dampak Deepfake Technology Terkait Perlindungan Data Pribadi Terhadap Hukum Nasional Indonesia}

Dalam hukum nasional di Indonesia sendiri belum ada UndangUndang yang mengatur khusus tentang data pribadi hanya berupa Rancangan Undang-Undang Perlindungan Data Pribadi yang belum disahkan, sedangkan, negara-negara di Eropa sudah memiliki aturan mengenai perlindungan data pribadi karena mereka menganggap data pribadi merupakan hal yang harus dilindungi. Jika kita melihat pada Undang-Undang Nomor 24 Tahun 2013 Tentang Perubahan atas Undang-Undang Nomor 23 Tahun 2003 Tentang Administrasi Kependudukan, Data Pribadi adalah data perseorangan tertentu yang disimpan, dirawat, dan dijaga kebenaran serta dilindungi kerahasiaannya. ${ }^{20}$ Tertulis jelas dalam Undang-Undang tersebut bahwa data perseorangan harus dilindungi kerahasiaanya.

Seperti yang telah penulis bicarakan sebelumnya mengenai Deepfake Technology, bahwasanya teknik ini menggunakan identitas wajah orang lain dalam suatu video photorealistic yang berpotensi merugikan orang lain. Secara konstitusional pun Negara melindungi privasi dan data penduduk masyarakat yang tertera pada pasal 28G ayat 1 Undang-Undang Dasar Negara Republik Indonesia 1945 yang

20 Undang-Undang Nomor 24 Tahun 2013 Tentang Perubahan atas Undang-Undang Nomor 23 Tahun 2003 Tentang Administrasi Kependudukan, pasal 1, butir 22 . 
berbunyi: Setiap orang berhak atas perlindungan diri pribadi, keluarga, kehormatan, martabat, dan harta benda yang di bawah kekuasaannya, serta berhak atas rasa aman dan perlindungan dari ancaman ketakutan untuk berbuat atau tidak berbuat sesuatu yang merupakan hak asasi. ${ }^{21}$

Dampak Deepfake Dechnology sendiri terhadap hukum nasional Indonesia terkait perlindungan data pribadi belum dapat mengikat secara penuh, karena Indonesia masih memiliki keterbatasan aturan mengenai perlindungan data pribadi. Pada umunnya Pasal 27 UU ITE yang digunakan untuk menjerat pelaku dalam kasus penyebaran informasi yang berbunyi: ${ }^{22}$

i. $\quad$ Setiap Orang dengan sengaja dan tanpa hak mendistribusikan dan/atau mentransmisikan dan/atau membuat dapat diaksesnya Informasi Elektronik dan/atau Dokumen Elektronik yang memiliki muatan yang melanggar kesusilaan.

ii. Setiap Orang dengan sengaja dan tanpa hak mendistribusikan dan/atau mentransmisikan dan/atau membuat dapat diaksesnya Informasi Elektronik dan/atau Dokumen Elektronik yang memiliki muatan perjudian.

iii. Setiap Orang dengan sengaja dan tanpa hak mendistribusikan dan/atau mentransmisikan dan/atau membuat dapat diaksesnya Informasi Elektronik dan/atau Dokumen Elektronik yang memiliki muatan penghinaan dan/atau pencemaran nama baik.

iv. Setiap Orang dengan sengaja dan tanpa hak mendistribusikan dan/atau mentransmisikan

21 Undang-Undang Dasar Negara Republik Indonesia 1945, pasal $28 \mathrm{G}$, ayat 1 .

22 Undang-Undang Nomor 11 Tahun 2008 Tentang Informasi dan Transaksi Elektronik, Pasal 27. 
dan/atau membuat dapat diaksesnya Informasi Elektronik dan/atau Dokumen Elektronik yang memiliki muatan pemerasan dan/atau pengancaman.

Tertulis setiap orang dengan sengaja dan tanpa hak mendistribusikan dan/atau mentransmisikan dan/atau membuat dapat diaksesnya informasi elektronik. Menurut saya pasal ini tidak dapat menjerat pembuat video yang berbentuk photorealistic tersebut, melainkan aturan hukum tersebut hanya dapat menjerat pelaku penyebaran video yang mengandung muatan yang melanggar kesusilaan, penghinaan, pencemaran nama baik, pemerasan dan pengancaman.

Dewasa ini terjadi bocornya video panas salah satu aktris di Indonesia yang berinisial GA yang berdurasi 19 detik. Pakar telematika di Indonesia, Roy Suryo ikut bersuara seputar video tersebut. Roy Suryo meminta seluruh pihak agar waspada jika video mirip GA tersebut bisa saja hasil manipulasi dari manipulasi sejumlah perangkat lunak seperti Deepfake. ${ }^{23}$ Dari video tersebut dilakukan analisa menggunakan Face Comparator (Recognizer) dan Face Matcher (Combiner) yang tingkat kecocokannya lebih dari 70 persen. Namun dari analisis video tersebut menjadi eksemplar yang dikaitkan dengan bahaya penggunaan Deepfake Technology terutama bagi Public

23 Liputan6, Pamer Hasil Analisa Video Mirip Gisel, Roy Suryo Minta Waspada Deepfake, https://www.liputan6.com/showbiz/read/ 4403933/pamer-hasil-analisa-video-mirip-gisel-roy-suryominta-waspada-deepfake, Diakses pada 17 November 2020.

Uti Possidetis: Journal of International Law, Vol. 2, No. 1 (2021) 
Figure, meski dalam hal ini kasus tersebut belum terbukti penggunaan Deepfake Technology itu sendiri.

\section{Keselarasan Pengaturan Serta Perlindungan Hukum Data Pribadi Dalam Ranah Hukum Internasional Terkait Deepfake Technology}

Penulis telah menyatakan bahwa tidak adanya aturan hukum secara spesifik terkait Deepfake Technology. Dengan menggunakan prinsip Planning, Organizing, Actuating, dan Controlling.

"Planning adalah sebuah proses di mana seorang manajer memutuskan tujuan, menetapkan aksi untuk mencapai tujuan (strategi) itu, mengalokasikan tanggung jawab untuk menjalankan strategi kepada orang tertentu, dan mengukur keberhasilan dengan membandingkan tujuan."24

Planning dalam penelitian ini dapat meliputi pengaturan tujuan dan mencari bagaimana cara untuk mencapai tujuan tersebut. Dalam hal ini yang menjadi tujuannya adalah untuk menyelaraskan aturan hukum internasional mengenai Deepfake Technology.

"Organizing adalah seluruh proses pengelompokan orang, alat, tugas, serta wewenang dan tanggung jawab sedemikian rupa sehingga tercipta suatu organisasi yang dapat digerakkan sebagai suatu kesatuan yang utuh dan

24 Yohannes Dakhi, SE, MM, Implementasi POAC Terhadap Kegiatan Organisasi Dalam Mencapai Tujuan Tertentu, Dosen STIE Nias Selatan, http://jurnal.dharmawangsa.ac.id/index.php/juwarta/article/vie w/204/199

Uti Possidetis: Journal of International Law, Vol. 2, No. 1 (2021) 
bulat dalam rangka pencapaian tujuan yang telah ditentukan sebelumnya."25

Pada penelitian ini udah sebutkan ada persatuan internasional yang bernama International Telecommunication Union yang menjadi suatu kesatuan utuh dalam rangka pencapaian tujuan yang telah ditentukan, yaitu menyelaraskan aturan hukum internasional terkait Deepfake Technology. Karena terkait Pasal 17 butir 1 Convention of the International Telecommunication Union menjelaskan fungsi mereka yang berbunyi: 26

"The functions of the Telecommunication Standardization Sector shall be, bearing in mind the particular concerns of the developing countries, to fulfil the purposes of the Union relating to telecommunication standardization, as stated in Article 1 of this Constitution, by studying technical, operating and tariff questions and adopting recommendations on them with a view to standardizing telecommunications on a worldwide basis."

Jika diterjemahkan fungsi dari International Telecommunication Union merujuk dari konvensi tersebut adalah dengan mempertimbangkan keprihatinan tertentu atas negara berkembang, untuk memenuhi tujuan-tujuan dari Union terkait standarisasi telekomunikasi, sebagaiana dinyatakan di Pasal 1 konstitusi ini, dengan mempelajari pertanyaan-

25 Ibid.

26 Convention of the International Telecommunication Union (with annexes and optional protocol). Concluded at Geneva on 22 December 1992, Article 17 
pertanyaan pengoperasian teknis dan tarif dan mengadopsi rekomendasi terhadapnya dengan pandangan untuk menstandarisasikan telekomunikasi pada skala worldwide.

Selanjutnya Actuating,

"Actuating merupakan upaya untuk merealisasikan suatu rencana. Dengan berbagai arahan dengan memotivasi setiap karyawan untuk melaksanakan kegiatan dalam organisasi, yang sesuai dengan peran, tugas dan tanggung jawab. Maka dari itu, actuating tidak lepas dari peranan kemampuan leadership. ${ }^{27}$

Dengan International Telecommunication Union merealisasikan rencana membuat aturan hukum internasional terkait Deepfake Technology dengan berbagai arahan kepada Negara-Negara Internasional maka terjadilah keselarasan hukum internasional tentang perlindungan data pribadi terkait Deepfake Technology.

Dan yang terakhir Controlling,

"Menurut G.R Terry, pengawasan dapat didefinisikan sebagai proses penentuan, apa yang harus dicapai yaitu standar, apa yang sedang dilakukan yaitu pelaksanaan, menilai pelaksanaan dan apabila perlu melakukan perbaikan-perbaikan, sehingga pelaksanaan sesuai dengan rencana yaitu selaras dengan standar." 28

Dengan demikian setelah terealisasikannya keselarasan hukum internasional terhadap perlindungan data pribadi terkait Deepfake Technology, International Telecommunication Union harus melakukan proses pengawasan pelaksanaan

27 Yohannes Dakhi, SE, MM, Op. Cit.

28 Ibid.

Uti Possidetis: Journal of International Law, Vol. 2, No. 1 (2021) 
penyelarasan hukum internasional terhadap perlindungan data pribadi terkait Deepfake Technology dan apabila perlu melakukan perbaikan-perbaikan sehingga pelaksanaan tersebut sesuai dengan rencana.

\section{Pengaturan Hukum Nasional terhadap Perlindungan Data Pribadi Terkait Deepfake Technology}

Sejauh ini dengan kekosongannya aturan spesifik terkait Deepfake Technology pemerintahan Indonesia seharusnya merancang sebuah aturan terkait penyalahgunaan teknik Deepfake dengan menimbang pada aturan hukum yang sudah ada. Seperti Pasal 315 KUHP yang berbunyi: ${ }^{29}$

"Tiap-tiap penghinaan dengan sengaja yang tidak bersifat pencemaran atau pencemaran tertulis yang dilakukan terhadap seseorang, baik di muka umum dengan lisan atau tulisan, maupun dimuka orang itu sendiri dengan lisan atau perbuatan, atau dengan surat yang dikirimkan atau diterimakan kepadanya, diancam karena penghinaan ringan dengan pidana penjara paing lama empat bulan dua minggu atau pidana denda paling banyak empat ratus ribu lima ratus rupiah."

Pada pasal tersebut jika dikembangkan menjadi rumusan UU ITE yang baru dapat mengikat orang yang melakukan dengan sengaja menggunakan Deepfake Technology menggunakan identitas wajah seseorang untuk menghina orang lain dalam dunia maya dapat dikenakan pidana.

Selanjutnya jika kita menimbang pada Pasal 1365 Kitab Undang-Undang Hukum Perdata yang berbunyi: ${ }^{30}$

29 Kitab Undang-Undang Hukum Pidana, Pasal 315.

30 Kitab Undang-Undang Hukum Perdata, Pasal 1365.

Uti Possidetis: Journal of International Law, Vol. 2, No. 1 (2021) 
"tiap perbuatan yang melanggar hukum dan membawa kerugian kepada orang lain, mewajibkan orang yang menimbulkan kerugian itu karena kesalahannya untuk menggantikan kerugian tersebut."

Dapat dikategorikan bahwa penyalahgunaan teknik Deepfake adalah perbuatan melanggar hukum dan akan menyebabkan kerugian kepada orang lain maka dari itu perlu mengganti atas kerugian yang telah diperbuat.

\section{Penutup}

Pemanfaatan Deepfake Technology dapat membawa pengaruh positif, dalam artian jika ingin mengembangkan industri perfilman, dengan hal ini dilakukan juga untuk menghemat biaya proses pengontrakan aktor atau aktris tertentu. Namun dibalik positifnya terlalu banyak Negatifnya jika Deepfake Technology disalahgunakan, sebagai contoh seorang Public Figure digunakan identitas wajahnya untuk melakukan provokasi, SARA, pencemaran nama baik untuk kepentingan politik yang mana dewasa ini sangat sensitif sekali jika terjadi hal-hal yang tidak diinginkan seperti ini. Jelas Deepfake Technology dapat berpotensi mengubah sudut pandang netizen pada zaman teknologi seperti sekarang. Pakar telekomunikasi di Indonesia pun telah menghimbau bahwa masyarakat harus waspada terhadap Deepfake Technology. Selain teknologi ini membutuhkan aturan hukum, instansi terkait pengembangan teknologi juga harus mengedukasi masyarakat akan teknik dan bahaya Deepfake. Dengan prinsip 
Planning, Organizing, Actuating, dan Controlling dunia Internasional dapat menyelaraskan aturan hukum terkait Deepfake Technology terhadap perlindungan data pribadi, dengan memanfaatkan keberadaan. Karena dizaman teknologi ini semua orang dari penjuru dunia dapat mengakses dunia internet dengan bebas dan dapat menggunakan Deepfake Technology. Oleh karena itu, hukum internasional akan memberikan tanggung jawab kepada negara untuk menjamin bahwa data pribadi warga masing-masing negara dilindungi sebagaimana mestinya.

\section{Referensi}

\section{Instrumen Hukum}

Constitution and Convention of the International Telecommunication Union (with annexes and optional protocol).Concluded at Geneva on 22 December 1992.

Convention for the protection of individuals with regard to the processing of personal data.

EU Charter of Fundamental Rights, Article 8 - Protection of personal data.

Kitab Undang-Undang Hukum Perdata, Pasal 1365. Kitab Undang-Undang Hukum Pidana, Pasal 315.

Kovenan Internasional Hak-Hak Sipil dan Politik (ICCPR), Pasal 17.

Peraturan Menteri Komunikasi dan Informatika Nomor 20 Tahun 2016 tentang Perlindungan Data Pribadi Dalam Sistem Elektronik

Undang-Undang Dasar Negara Republik Indonesia 1945, pasal $28 \mathrm{G}$, ayat 1 . 
Aspek Hukum Internasional dalam Pemanfaatan Deepfake...

Undang-Undang Nomor 11 Tahun 2008 Tentang Informasi dan Transaksi Elektronik

Undang-Undang Nomor 24 Tahun 2013 Tentang

Perubahan atas Undang-Undang Nomor 23

Tahun 2003 Tentang Administrasi

Kependudukan.

\section{BUKU}

J.G.Starke, Pengantar Hukum Internasional, Cet. 10, Sinar Grafika, Jakarta, 2010.

Peter Mahmud Marzuki, Penelitian Hukum Edisi Revisi, Prenadamedia Group, Jakarta, 2005

Russell, Stuart J.; Norvig, Peter (2009). Artificial Intelligence: A Modern Approach (3rd ed.). Upper Saddle River, New Jersey: Prentice Hall.

Satjipto Rahardjo, Hukum Progresif: Sebuah Sintesa Hukum Indonesia. Yogyakarta: Genta Publishing, 2009.

Sefriani, Pengantar Hukum Internasional (Rajagrafindo Persada 2015)

Soerjono Soekanto dan Sri Mamudji, Penelitian Hukum Normatif Suatu Tinjauan Singkat, CV. Rajawali, Jakarta, 1985

Stuart J. Russel and Peter Norvig, Artificial Intelligence A Modern Approach Third Edition, Pearson Education, Inc., New Jersey, 2010

\section{JURNAL}

Clarke, Yvette D, (28 June 2019), "H.R.3230 - 116th Congress (2019-2020): Defending Each and Every Person from False Appearances by Keeping Exploitation Subject to Accountability Act of 2019". www.congress.gov

Detection of Deepfake Video Manipulation, Marissa Koopman, Andrea Macarulla Rodriguez, Zeno 
Geradts.University of Amsterdam \& Netherlands Forensic Institute 2018.

Itsna Hidayatul Khusna \& Sri Pangestuti, Deepfake, Tantangan Baru Untuk Netizen, E ISSN: 24609633

Noval, Sayid. (2019). PERLINDUNGAN HUKUM TERHADAP KORBAN PENYALAHGUNAAN DATA PRIBADI: PENGGUNAAN TEKNIK DEEPFAKE.

Retno Kusniati, Jurnal Sejarah Perlindungan Hak Hak Asasi Manusia Dalam Kaitannya Dengan Konsepsi Negara Hukum. Jurnal Ilmu Hukum, Vol. 4. No. 5. 2011, https://onlinejournal.unja.ac.id/jimih/article/view/536

Yohannes Dakhi, Implementasi POAC Terhadap Kegiatan Organisasi Dalam Mencapai Tujuan Tertentu, Dosen STIE Nias Selatan, http://jurnal.dha rmawangsa.ac.id/index.php/juwarta/article/vi ew/204/199

\section{Website}

Adhi Maulana, Tingkat Kejahatan Cyber Di Indonesia Sudah Gawat, http://tekno.liputan6 .com/r ead/2019078/tingkat-kejahatan-cyber-di indo nesia-sudahgawat, 6 Maret 2014.

Black's: Law Dictionary Online, https://thelawdictionary.org/technology/.

CNN, "RUU Data Pribadi Terancam Tak Selesai Dibahas

Tahun Ini", https://www.cnnindonesia.com /teknologi/20190807122353-185419154/ruudata-pribadite rancam-tak-selesai-dibahastahun-ini

Kamus Besar Bahasa Indonesia Online/Daring ,https://kbbi.web.id/aspek

Kamus Besar Bahasa Indonesia Daring, "Kecerdasan Buatan", 
Aspek Hukum Internasional dalam Pemanfaatan Deepfake...

https://kbbi.kemdikbud.go.id/entri/kecerdasa n\%20buatan,

Liputan6, Pamer Hasil Analisa Video Mirip Gisel, Roy Suryo Minta Waspada Deepfake, https://www.liputan6.com/showbiz/read/440 3933/pamer-hasil-analisa-video-mirip-giselroy-suryo-minta-waspada-deepfake

Perfect Deepfake Tech Could Arrive Sooner Than Expected, www.wbur.org 